F. Maroto*, S. Gallego, C. Pérez y C. Colon

Unidad de Cuidados Intensivos, Hospital San Juan de Dios, Bormujos, Sevilla, España
* Autor para correspondencia.

Correo electrónico: fernando_maroto8@hotmail.com (F. Maroto).

doi:10.1016/j.medin.2010.07.013

\section{Sección de los músculos rectos del abdomen por cinturón de seguridad}

\section{Section of rectus abdominis muscle by the safety belt}

\section{Sr. Director:}

El cinturón de seguridad ha disminuido la morbimortalidad de los accidentes de tráfico, pero su utilización puede producir lesiones graves. Presentamos el caso de un varón que sufrió un accidente de automóvil al que la utilización del cinturón de seguridad provocó la rotura transversal de los músculos rectos anteriores.

Varón de 13 años que sufrió un accidente de tráfico con choque frontal cuando viajaba en el asiento posterior

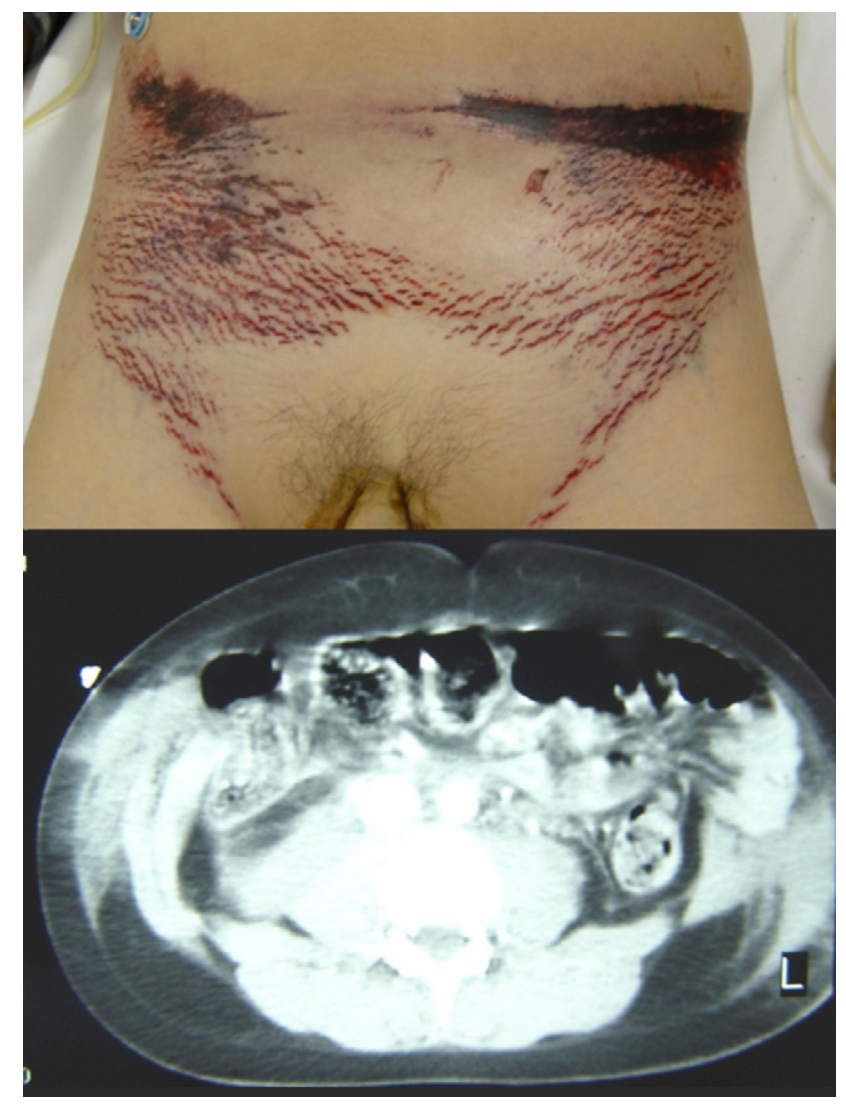

Figura 1 La equimosis infraumbilical causada por el cinturón de seguridad durante la desaceleración se corresponde, en la TAC abdominal, con una dehiscencia de rectos anteriores, eventración del contenido intestinal en ese área y un gran hematoma en las paredes laterales del abdomen. izquierdo del automóvil. A su llegada al hospital destacaba hipotensión de $90 / 40 \mathrm{mmHg}$, taquicardia de 110 latidos y taquipnea; dibujando la posición del cinturón de seguridad, presentaba equimosis cutáneas en el cuello y el tórax y un gran hematoma a $10 \mathrm{~cm}$ por debajo del ombligo; en las extremidades se objetivó parálisis flácida del brazo izquierdo sin deformidades y con los pulsos periféricos conservados. Una TAC abdominal detectó dehiscencia de los músculos rectos anteriores con eventración a su través de asas intestinales y, a ambos lados, hematoma de partes blandas (fig. 1). La cirugía confirmó la sección transversal de ambos rectos anteriores con evisceración encubierta, rotura de las aponeurosis de los músculos oblícuos, hemoperitoneo y rotura del meso intestinal a $90 \mathrm{~cm}$ del ángulo de Treitz. Se le practicó una sutura del meso y ligadura de vasos epigástricos que sangraban. La paresia flácida del brazo izquierdo se diagnosticó de lesión del plexo braquial (C6-C7 y D1) mediante un estudio neurofisiológico.

El síndrome de cinturón de seguridad fue descrito en 1962 en relación con la fuerza de desaceleración ejercida sobre un pasajero contenido con este sistema: 1) lesiones cutáneas equimóticas que "dibujan el cinturón de seguridad"1; 2) lesiones intraabdominales por la compresión por la banda pélvica del cinturón; y 3) fracturas vertebrales por hiperflexión brusca de la columna. Thomson ${ }^{2}$ recogió tres patrones cinéticos de lesión abdominal en niños: 1) mala colocación del cinturón; 2) mala posición del niño; y 3) utilización inadecuada de la banda del hombro. En el caso presentado se produjo una lesión compleja de la pared abdominal acompañada de daño del plexo braquial izquierdo; el mecanismo lesional probable fue la banda pélvica demasiado alta, infraumbilical, y la banda del hombro mal adaptada a la talla del pasajero. La rotura transversal de los rectos tuvo una manifestación llamativa, que facilitó la localización de la causa de la inestabilidad y su tratamiento precoz.

En caso de accidente de tráfico, en presencia de hematomas en la piel subyacente a la banda pélvica del cinturón, cabe la posibilidad de que se hayan producido lesiones graves de la pared abdominal ${ }^{3}$. La rotura de los rectos anteriores del abdomen es una lesión potencialmente grave por asociarse a desgarro y sangrado de las arterias epigástricas; la presencia de hematoma como estigma cutáneo es clave para su diagnóstico.

\section{Bibliografía}

1. Arbogast KB, Kent RW, Menon RA, Ghati Y, Durbin DR, Rouhana SW. Mechanisms of abdominal organ injury in seat beltrestrained children. J Trauma. 2007;62:1473-80.

2. Thompson NS, Date R, Charlwood AP, Adair IV, Clements WD. Seat-belt syndrome revisited. Int J Clin Pract. 2001;55:573-5. 
3. Porter RS, Zhao N. Patterns of injury in belted and unbelted individuals presenting to a trauma centre after motor vehicle crash: seat belt syndrome revisited. Ann Emerg Med. 1998;32:418-24.

A. Ambrós Checa, S. García-Velasco Sánchez-Morago* y H. Abdel-Hadi Álvarez

Servicio de Medicina Intensiva, Hospital General de Ciudad Real, Ciudad Real, España
* Autor para correspondencia. Correo electrónico: santgarc@gmail.com (S. García-Velasco Sánchez-Morago).

doi:10.1016/j.medin.2010.09.005

\section{Experiencia con tigeciclina en el tratamiento de gérmenes multirresistentes en $\mathrm{UCl}$}

\section{Experience with tigecycline in the treatment of multiresistant germs in the ICU}

\section{Sr. Director:}

La tigeciclina es un antibiótico perteneciente al grupo de las glicilglicinas, con potente actividad frente a una amplia variedad de microorganismos, incluidos los multirresistentes ${ }^{1}$. Actúa bloqueando la síntesis proteica mediante la fijación del complejo aminoácido-ARN al ribosoma.

Aunque las indicaciones aprobadas por la Food and Drug Administration (FDA) no son idénticas a las de la European Medicines Agencie (EMEA) ${ }^{1}$, su uso en nuestro país está limitado a las indicaciones avaladas por los estudios clínicos realizados, que consisten básicamente en infecciones intraabdominales e infecciones complicadas de piel y tejidos blandos. Sin embargo en la práctica clínica, su utilización se amplía para el tratamiento de infecciones graves por gérmenes multirresistentes ${ }^{2,3}$.

Hemos analizado durante el pasado año 2009 las indicaciones y resultados del tratamiento con tigeciclina en la $\mathrm{UCl}$ de un hospital de tercer nivel. Para ello, se definió la respuesta clínica como positiva cuando hubo mejoría parcial o total de signos y síntomas de infección, negativa cuando no hubo mejoría o hubo deterioro clínico, e incierta cuando no hubo datos que nos permitieron conocerla.

La respuesta microbiológica se consideró positiva cuando se negativizaron los cultivos de control a partir del $5^{\circ}$ día de tratamiento, negativa cuando persistía el microorganismo a pesar de tratamiento correcto, y no documentada cuando no se realizaron cultivos de control.

Se realizaron 44 tratamientos con tigeciclina durante al menos 1 semana, en pacientes de 48,1 $\pm 15,5$ años, siendo el $81,8 \%$ hombres. La gravedad de los pacientes al ingreso, medida como mediana (y rango intercuartílico) de APACHE fue 22 (16-28). El motivo de ingreso fue por patología médica en $43,2 \%$, trauma en $29,5 \%$ o quirúrgica en $27,3 \%$. Hasta un $82 \%$ no tuvieron comorbilidades importantes.

La localización más frecuente de la infección fue del tracto respiratorio $(51,2 \%)$ siendo el $27,3 \%$ neumonía asociada a ventilación mecánica, traqueobronquitis $20,4 \%$ y neumonía de la comunidad en $2,3 \%$. Otras localizaciones menos frecuentes fueron piel y herida quirúrgica en $13,6 \%$, intraabdominal en $13,6 \%$, bacteriemia primaria en $9,1 \%$ e infección por catéter en 4,5\%. Las indicaciones fueron según ficha técnica únicamente en un $27,9 \%$ y en un $9,3 \%$ se usó de forma empírica.

El germen para el que se utilizó fue Acinetobacter baumanii $(81,4 \%)$, Klebsiella pneumoniae $(4,7 \%)$ y Enterococcus faecalis $(4,7 \%)$.

El perfil de resistencias del acinetobacter en nuestra unidad se ha ido modificando durante los últimos años, pero globalmente podemos decir que tenemos un $83,8 \%$ de resistencias a carbapenemes y un 74,4\% a ampicilina-sulbactam. Los fármacos testados con menos resistencias, son la amikacina $(9,3 \%)$, colistina $(7,6 \%)$, la y la tigeciclina $(4,2 \%)$.

En al menos el $74,4 \%$ se utilizó en combinación con otro antibiótico: colistina intravenosa en $25,6 \%$, colistina aerosolizada en $32,6 \%$ o amikacina en el $14 \%$, siendo datos muy parecidos a los publicados por Alvarez Lerma et al recientemente 4

Se observó una respuesta clínica positiva en el 67,4\% y negativa en el $30,2 \%$, aunque la respuesta microbiológica fue peor (37,2\% negativizó cultivos, 34,9\% persistieron cultivos positivos y carecemos de datos en $27,9 \%$ ). En ningún caso de persistencia microbiológica se objetivó la aparición de resistencia a tigeciclina.

Como conclusión podemos extraer que la tasa de uso compasivo de tigeciclina en nuestro centro (fuera de las indicaciones aprobadas) ha sido muy elevada, y que ha supuesto una nueva arma de gran ayuda contra gérmenes multirresistentes en entornos de cuidados intensivos, generalmente en asociacion con colistina, como tratamiento de rescate o como uso compasivo, mostrando una buena respuesta clínica y en algunos trabajos, un descenso de la mortalidad $^{5}$.

\section{Bibliografía}

1. Reinert RR, Low DE, Rossi F, Zhang X, Wattal C, Dowzicky MJ. Antimicrobial susceptibility among organisms from the Asia/Pacific Rim. Europe and Latin and North America collected as part of TEST and the in vitro activity of tigecycline. J Antimicrob Chemother. 2007;60:1018-29.

2. Betriu C, Rodriguez-Avial I, Lopez F, Picazo JJ. Comparative study of the in vitro activity of tigecycline against multiresistant Enterococcus faecium isolates. Enferm Infecc Microbiol Clin. 2009;27:302-3. 